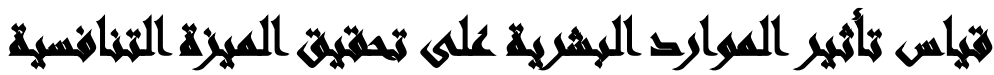

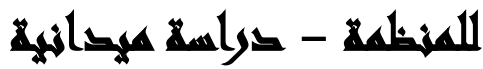

\section{[1T]}

داليا صلاح الدين عطيه العطار (') - جمال سعد خطاب(') - صلاح حسن سلام (1) () كلية التجارة، جامعة عين شمس الاين عطيه

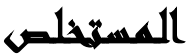

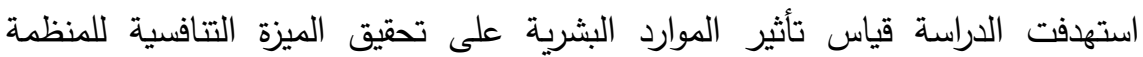

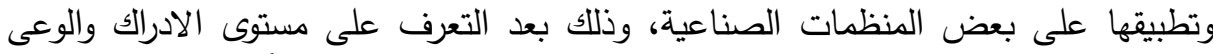

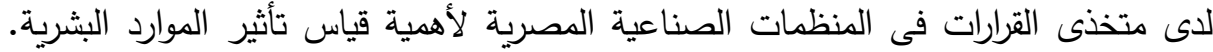

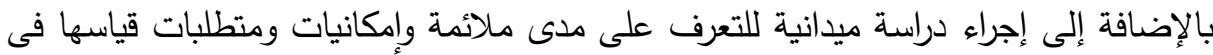

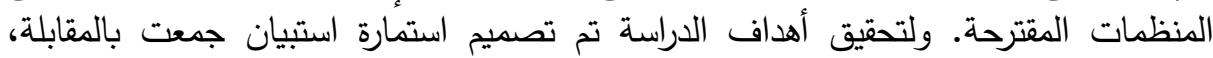

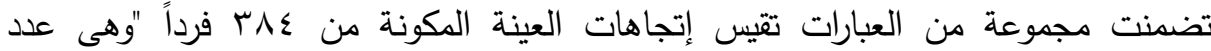

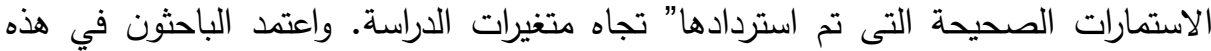

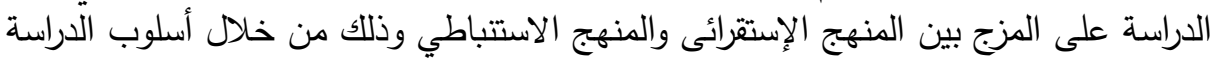
النظرية والدراسة الميدانية، وقد أجرى الباحثون تحليل البيانات باستخدام الإنتار كروسكال

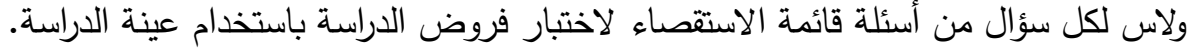

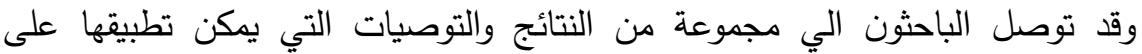



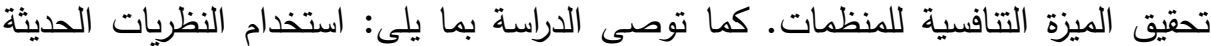

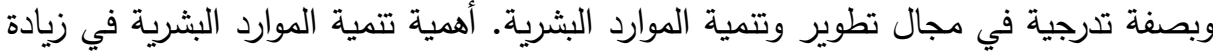

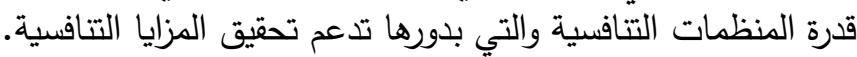
كلمات مفتاحية: تتمية الموارد البشرية، الميزة التتافسية.

\section{$x$}

أدركت المنظمات في ظل تحولات البيئة التتافسية أن العامل الإنتاجي الوحيد الذي يمكن أن يوفر لها الميزة التتافية المتواصلة هو رأسمالها الفكري، ذو المعرفة والمهارات العالية

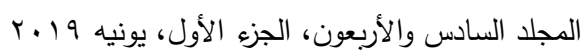


القادرة على الإبداع، ومن ثم التحول من اقتصاد المعلومات إلى اقتصاد المعرفة والعقول

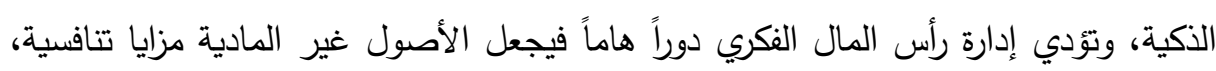

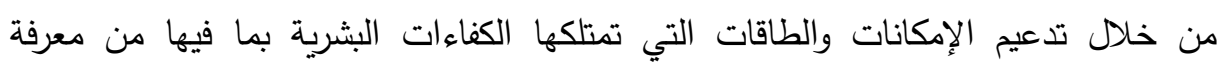

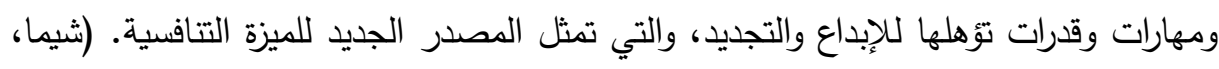

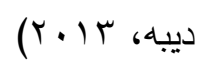
ويعد رأس المال البشرى من الأدوات الهادفة الواجب أخذها في الاعتبار عند تحديد

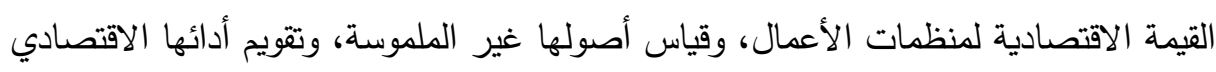
الذي يؤثر بالتبعية على أسعار أسهمها وزيادة حدة المنافسة بين هذه المنظمات، كما أن تقديم التئي

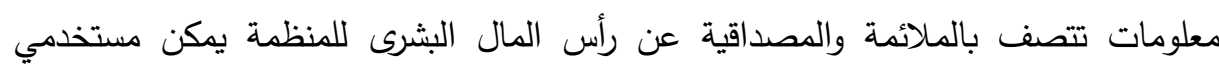
المعلومات من التعرف على كفاءة أسواق رأس المال عن طريق إمداد المستثمرين الحاليين

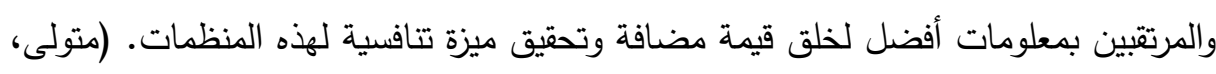

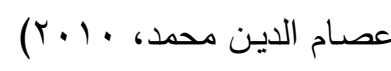
ان نجاح المنظمات فى بيئة المنافسة الحادة اصبح مرهونا بقيمة هذا الأصل واستراتيجيات ادارته وذلك بسبب دوره الفعال فى تعزيز ميزة المنظمة التنافسية وخلق القيمة، ولن يتحقق هذا الأمر إلا إذا امتلكت هذه المنظمات الكوادر البشرية المؤهلة مع توفير ثقافة دورة

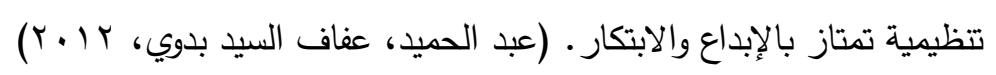

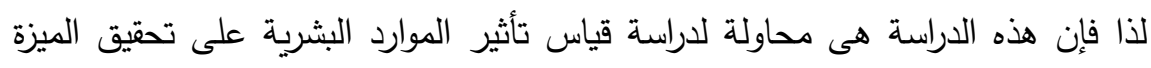

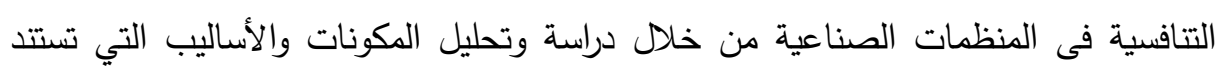
إليها الإدارة فى هذه المنظمات بقصد تتمية وتطوير الموارد البشرية بما يسهم فى رفع أداء


للميزة التتافسية.

\section{ميف2ل التصواسمة}

يعتبر القطاع الصناعى من القطاعات الهامة والرئيسية والأكثر حيوية فى أى دولة،

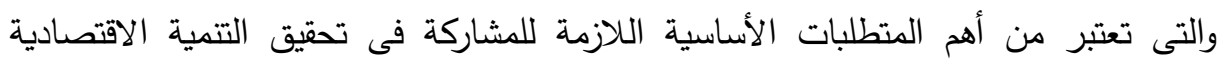

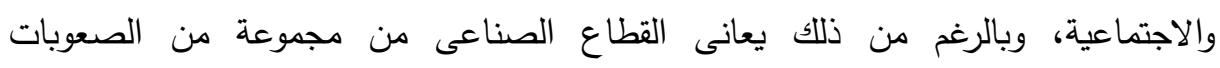
276

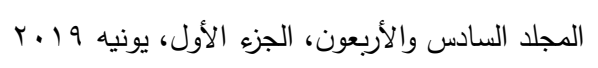


والمشكلات التى تواجه المنظمات على اختلاف انواعها واحجامها فى قياس تأثير رأس المال

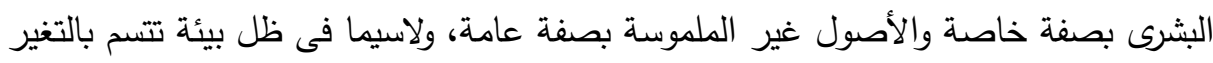
المستمر ، ولا شك ان ذلك ينعكس بدوره على مدى تمتع المنشأة بالمزايا التتافسية من خلال

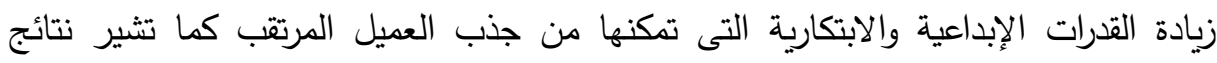
الدراسات السابقة التى أجريت على بعض الدنظمات، على وجود مجموعة من الظواهر الدالة

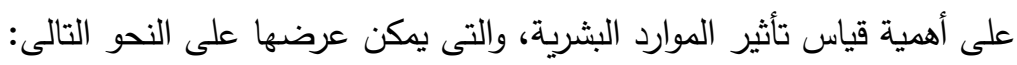
- ان تتمية الكفاءات تؤدي إلى تميز وتفوق الفردفي انجاز مهامها الوظيفية وأيضا نجاح المؤسسة وتحقيق أهدافها للحصول على إنتاجية عالية وجودة لتحقيق ميزة تتافسة في لني السوق.

- تستفيد المنظمات التى تعتمد على تتمية الموارد البشرية وممارسات إدارة الموارد البشرية التي تؤدي إلى نظم عمل عالية الأداء.

- ممارسات الموارد البشرية التي تصل الى أعلى مستويات التحفيز يمكن أن تولد أيضا ميزة تتافسية مستدامة بالرغم من الضغوط التتافسية عندما تكون ضمنية وفى سياق معين. - المنظمات التى لديها استثمارات كبيرة فى أصول المعرفة ورأس المال الفكرى والموارد البشرية، تمكنت من توليد ميزة تتافسية كبيرة.

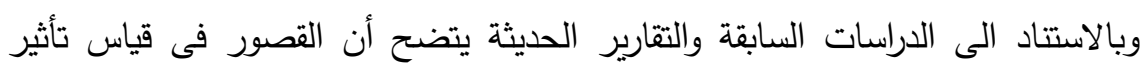
الموارد البشرية والنقص فى قدرات الابتكار والابداع يؤثر على تحقيق الميزة التتافسية لدى المنظمات الصناعية المصرية فى ظل التغيرات المحيطة.

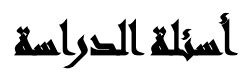

إلى أي مدى يساهم قياس تأثير رأس المال البشري في تحقيق الميزة التتافسية لاى المنظمات الصناعية المصرية؟ وينبثق من هذا التساؤل الرئيسى التساؤلات الفرعية التالية:

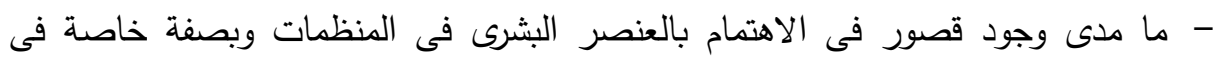



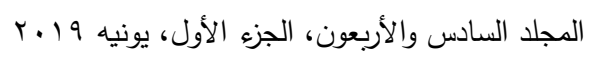


- الى اى مدى يؤدى القصور فى قياس تأثير العنصر البشرى الى قصور قدرات الابتكار والابداع؟

- الى اى مدى يؤدى القصور فى قياس تأثير رأس المال البشرى الى ضعف المحتوى

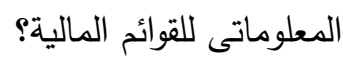

- ما الأساليب اللازمة لقياس تأثير رأس المال البشرى؟

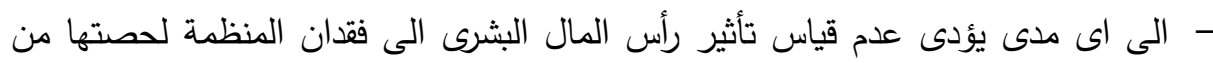

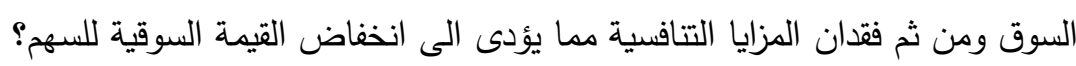

\section{أهساهنغ التراسمة}

يتمثل الهدف الرئيسى للدراسة فى التوصل إلى قياس لتأثير الموارد البثرية فى تحقيق

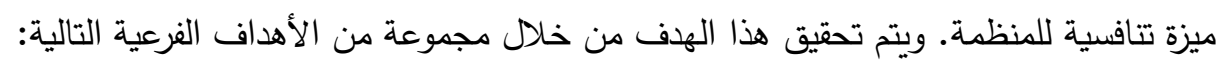

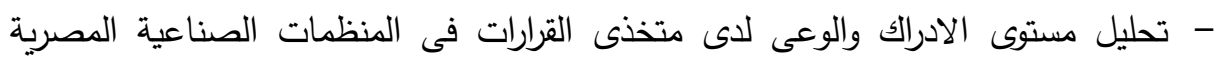
لأهمية قياس تأثير الموارد البشرية. - تحديد أوجه القصور فى قياس تأثير الثيثر الموارد البشرية وتأثير ذلك على أداء الدنظمات الصناعية المصرية. - توضيح كيفية قياس تأثير الموارد البشرية فى ظل المتغيرات البيئية. - وضع اطار مقترح لقياس تأثير رأس المال البثرى على الثئ الميزة التتافسية.

\section{أهمه الدواسمة}

تتمثل أهمية الدراسة فى الجانب (الثخصى) والجانب (التطبيقى) والجانب العلمى (الأكاديمى)

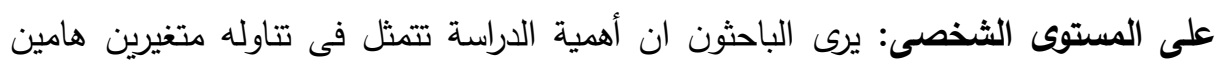
على مستوى الدراسات الاجتماعية والإنسانية وهما الموارد البشرية والمزايا التنافسية.

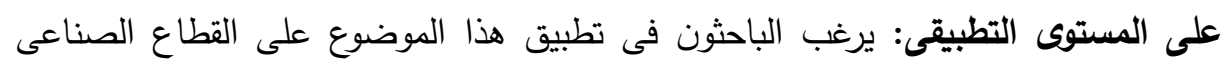

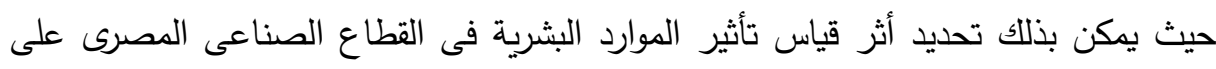
تحقيق الميزة التنافسية وذلك من خلال تطبيق مجموعة من البرامجالاحصائية.

$$
\text { المجلد السادس والأربعون، الجزء الأول، يونيه } 19
$$


على المستوى الأكاديمى: تأتى هذه الدراسة دعماً لغيرها من الدراسات السابقة وتضيف اليها

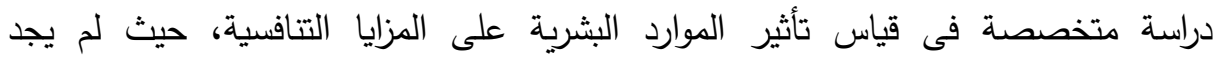
الباحثون- فى حدود اطلاعهم- دراسة تربط بين تلك المتغيرات على المستوى المحلى.

\section{السراسايه الساريخها}

قام الباحثون بتتاول أهم الدراسات السابقة العربية والأجنبية المتعلقة بمشكلة الدراسة فى تصى ضوء ما توافر لها والتى تتاولت مفهوم وأهمية قياس تأثير الموارد البشرية على تحقيق الميزة التتافسية. وتتاول الباحثون فيما يلى أهم هذه الدراسات طبقاً للتسلسل التاريخى. الدراسات السابقة التى تناولت مفهوم وأهمية قياس تأثير الموارد البشرية التهاتية باللغة العربية: دراسة مرهج (7 1 • Y): هدفت هذه الدراسة للتعرّف على العلاقة بين رأس المال الفكري وأداء الابتكار في جامعة تشرين، من خلال تحديد تأثير رأس المال البشري، والهيكلي، والعلاقاتى. وتوصلت الدراسة إلى ما يلى: تبين امتلاك جامعة تشرين لرأس مال بشري قادر على على أداء

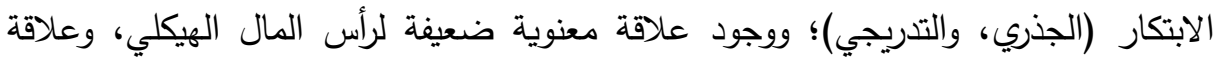

$$
\text { معنوية قوية لرأس المال العلاقاتى، وأداء الابتكار . }
$$

الاراسات السابقة الأجنبية التى تناولت مفهوم وأهمية قياس تأثير الموارد

Aldulaimi, Saeed Hameed, 2016 هدفت الدراسة إلى التعرف على العوامل

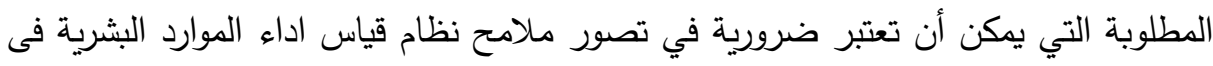
الوحدات التظظيمية الحديثة. وتوصلت الدراسة إلى ما يلى: تحديث الكتابات الاكاديمية

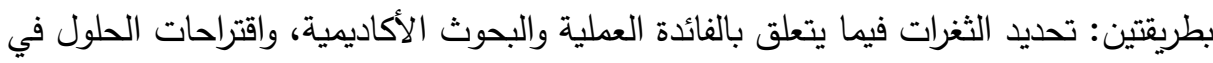

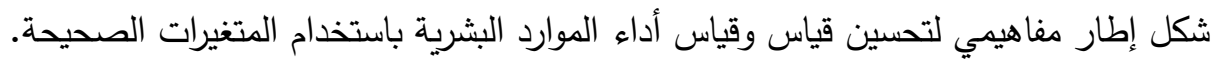




\section{الدراسات السابقة التى تناولت تحقيق المزايا التنافسية باللغة العربية:} دراسة محلب (10 • †): هدفت الدراسة الى توضيح العلاقة بين التحليل البيئي والمزايا التتافسية للمؤسسات، وبيان إدراك المسيرين لأهمية التحليل البيئي في بناء وتطوير المزايا

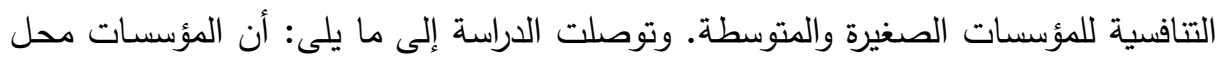

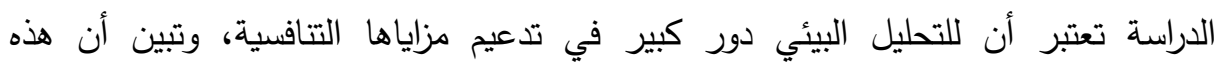
المؤسسات تعرف نقاط قوتها ونقاط ضعفها وتعمل على تقصي بيئتها الخارجية من أجل تعزيز مزاياها التنافسية.

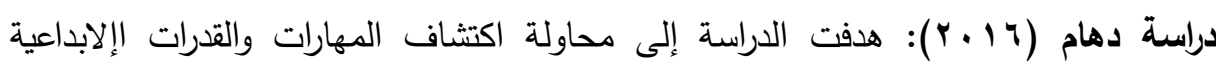



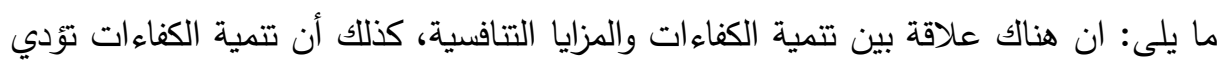
إلى تميز وتفوق الفردفي انجاز مهامه الوظيفية وأيضا نجاح المؤسسة وتحقيق أهدافها للحصول على إنتاجية عالية وجودة لتحقيق ميزة تتافسة في السوق.

\section{الدراسات السابقة الاجنبية التى تناولت تحقيق المزايا التنافسية:} Al-najjar, Fayez Jomah, 2016 المسؤولية الاجتماعية على المزايا التتافية لشركات الاتصالات السلكية واللاسلكية الأردنية.

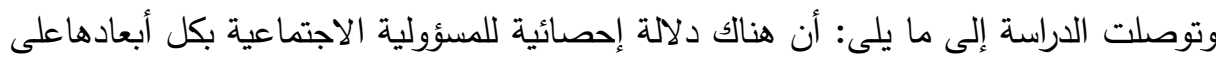
المزايا التنافسية في شركات الاتصالات الأردنية. الدراسات السابقة التى تناولت قياس تأثير الموارد البشرية وتحقيق الأنية العزايا

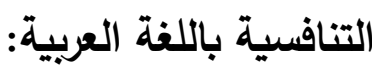
دراسة الحدراوى (10 • ؟): هدفت الدراسة الى التعرف على مراحل التدريب ودورها فى تحقيق المزايا التتافسية المستدامة. وتوصلت الدراسة إلى ما يلى: وجود حاجة متزايدة لتدريب الموارد

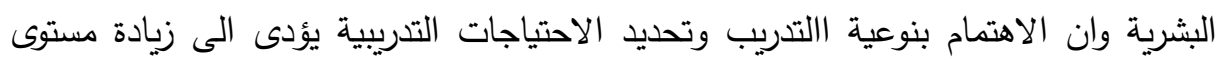
كفاءة العاملين وبالتالى يؤدى الى تحقيق ميزة تتافسية مستدامة. 
دراسة لويزة (1 1 × Y): هدفت الدراسة الى تحديد أثر قياس رأس المال الفكري بأبعاده على

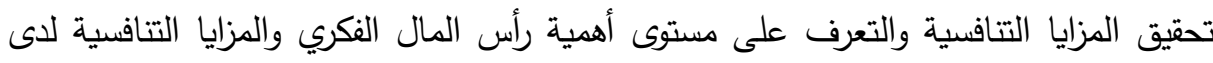

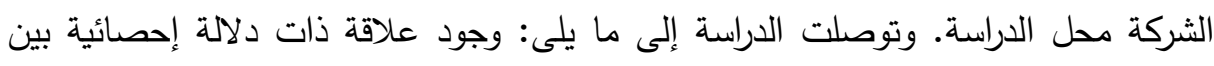
رأس المال الفكري بأبعاده الثلاثة خاصة البشرى وتحقيق المزايا التتافسية في الثركة محل دله دله الدراسة.

الدراسات السابقة الاجنبية التى تناولت قياس الموارد البشرية وتحقيق المزايا التنافسية: Manroop, Laxmikant, 2015 هدفت الدراسة الى معرفة كيف تسهم نظم الموارد البشرية فى المزايا التنافسية بتيسير التطوير والصيانة لخمسة أنواع من المناخات الأخلاقية.

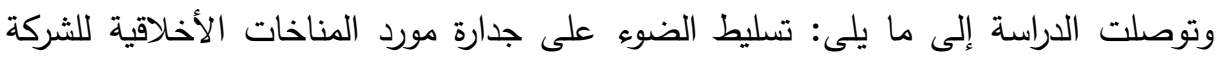

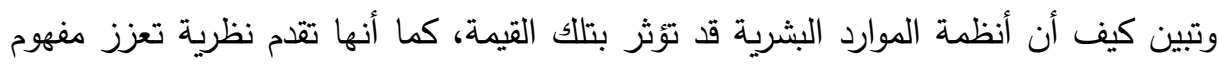
المزايا التنافسية المستدامة.

\section{الإلطار اللنظليه}

تثمل الدراسة على عدد من المفاهيم التي لابد من توضيحها وتحديد المقصود منها وهي على النحو التالي: تصني تنمية الموارد البشرية: بأنها عملية مخططة موضوعيا ومتكاملة وقائمة على معلومات صحيحة وتهدف إلى إيجاد قوة عمل تتاسب متطلبات العمل في منظمات محددة، وتتفهر إمكانيات وظروف وقواعد وأساليب الأداء المطلوب، وتكون قادرة على تطبيق تلأك القواعد والأساليب وترغب في أداء الأعمال باستخدام ما لديها من قدرات ومهارات (أبو النصر ، ونكات

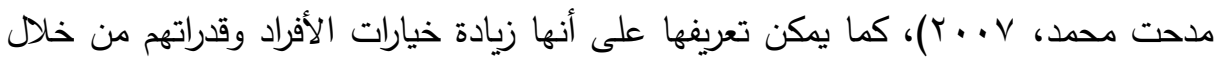

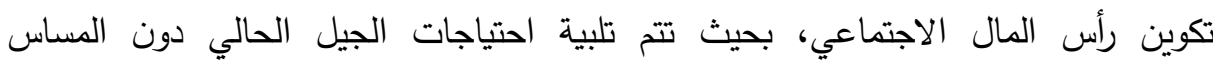

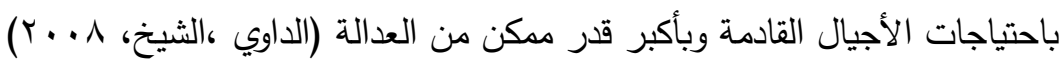

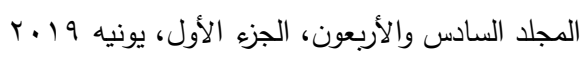


الميزة التنافسية: بأنها قابلية المنظمة على الأداء بأسلوب واحد أو عدة أساليب ليس

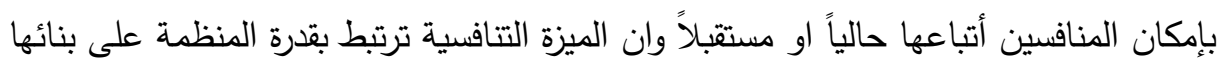





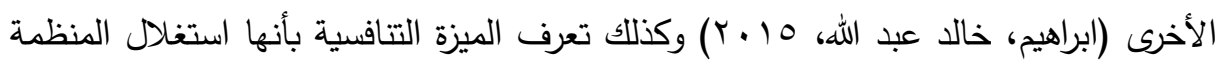

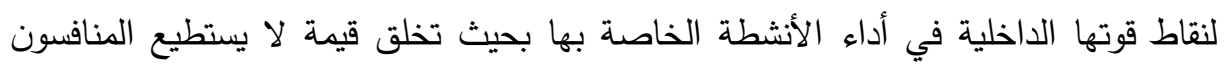



\section{هنهمج السواسلة}

فى ضوء طبيعة المشكلة وهدف وأهية الدراسة بنى هذا المنهج على الجمع بين الدراسة النظرية والدراسة الميدانية كما يلى:

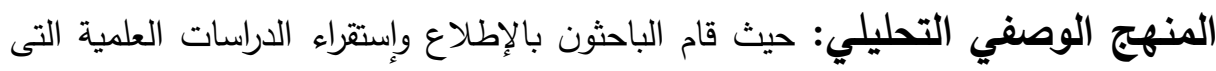

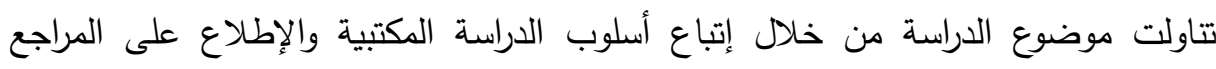

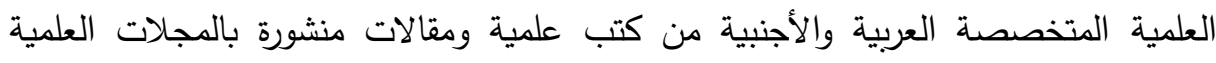

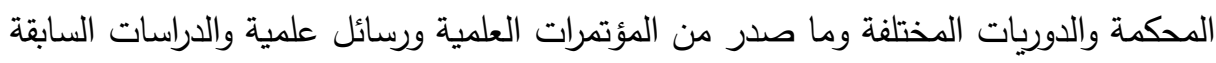

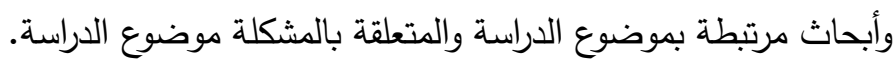

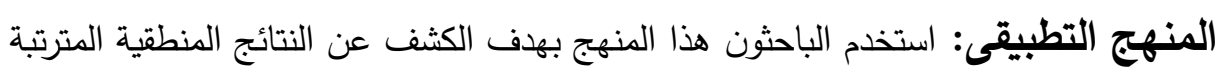

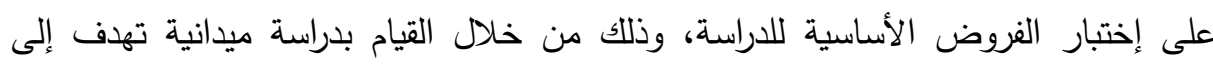

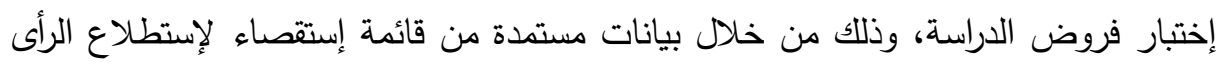
تم توزيعها على أفراد العينة الى جانب المقابلات الثخصية. 


\section{هروضش السراسما}

من أجل تفسير مشكلة الدراسة ومحاولة الإجابة عن الأسئلة المطروحة يمكن صياغة الفروض

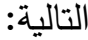
الفرض الأول: توجد علاقة ارتباط جوهرية بين كفاءة وفعالية تتمية الموارد البشرية فى المنظمة وبين قدراتها التتافسية. الفرض الثانى: توجد علاقة ارتباط جوهرية بين أسلوب تتمية الموارد البشرية ومستوى تدعيم



\section{إجباءاهـ الصراسة}

الاراسة الميدانية (المنهج التحليلي): تعتمد الدراسة الميدانية على منهج البحث الميداني، من خلال الاعتماد على قائمة استقصاء تم تصميمها وتطويرها لأغراض الدراسة، عمد الباحثون في إجراء الدراسة الميدانية على قائمة الاستقصاء والتي تم توزيعها على عينة من الأكاديميين: ويتمثلون في أساتذة الجامعات في منطقة القاهرة الكبرى (عين شمس، لوكيل القاهرة، حلوان)، وذلك للاستفادة بخبرتهم العلمية والأكاديمية في مجال الدراسة، أعضاء

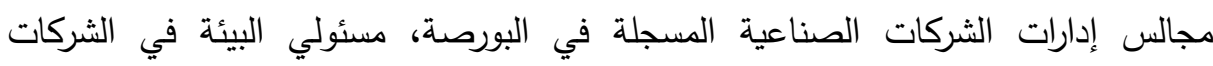

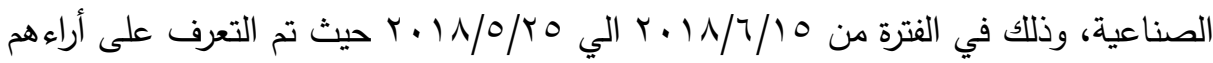
ورغباتهم واتجاهاتهم والعناصر الغير مرضية التى تواجههم وانطباعاتهم واقتراحاتهم، وقد تم استخدام الأساليب الإحصائية في تحليل البيانات والمعطيات التي تم جمعها.

\section{أسلوهب والتوايت الترواسما}

مجتمع الاراسة: يتمثل مجتمع الدراسة من الأكاديميين: ويتمثلون في أساتذة الجامعات في منطقة القاهرة الكبرى (عين شمس، القاهرة، حلوان)، وذللك للاستفادة بخبرتهم العلمية 
والأكاديمية في مجال الدراسة، أعضاء مجالس إدارات الشركات الصناعية المسجلة في البورصة، مسئولي البيئة في الشركات الصناعية. عينة الاراسة: كانت عينة الدراسة المكونة من ع^ب فرداً "وهى عدد الاستمارات الصحيحة التى تم استردادها"، ونظراً لطبيعة البيانات التى تتسم بندرة الاستجابة على بعض فض فئات الاستجابة خاصة فئة لا أوافق مطلقاً، فقد قام الباحثون بحساب قيمة كروسكال ولاس بإستخدام

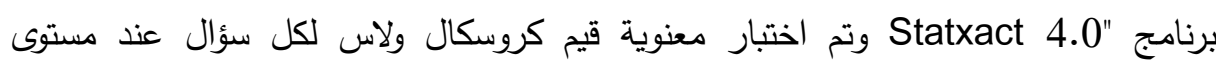
$\therefore, \cdot 0$

Sample Size تم اختيار عينة عشوائية بسيطة، وتم تحديد حجم العينة باستخدام برنامج

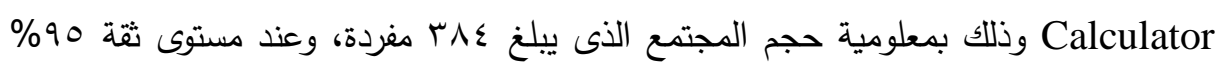
وحدود خطأ 土 ॰ \%، وبعد ادخال البيانات للبرنامج تم حساب حجم العينة. قياس متغيرات الدراسة: في ضوء الدراسات السابقة التي إطلع عليها الباحثون، فقد اعتمد الباحثون قياس المتغير المستقل (تأثير الموارد البشرية) والمتغير التابع (تحقيق الميزة التتافسيه). أداة تجميع بيانات الاراسة الميدانية: قام الباحثون بتصميم قائمة استقصاء لتجميع البيانات من مفردات الدراسة، حيث مر إعدادها وتصميمها بالخطوتين التاليتين: الخطوة الأولى: إعداد قائمة الاستقصاء فى صورتها الأولية: قام الباحثون بتصديم قائينة

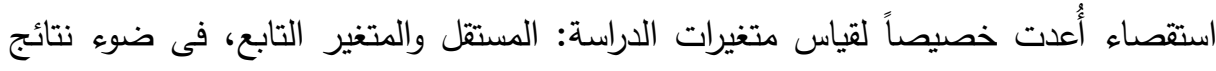
بعض البحوث والدراسات والكتابات العلمية السابقة، وكذللك فى ضوء ما كشفت عنه نتائج


حتى تتفق مع المستوى الثقافي لبعض المستقصين موضع الدراسة، هذا ويمكن توضيح عدد عبارات قائمة الاستقصاء من خلال الجدول التالى:

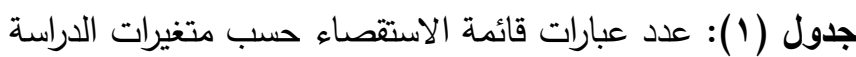

\begin{tabular}{|c|c|}
\hline عدد العبارات & متغيرات الدراسة \\
\hline 10 & قدرة المنظمة على تتمية الموارد البشرية \\
\hline YI & قدرة المنظمة على تحقيق الميزة التتافسية \\
\hline ry & آجمالى \\
\hline
\end{tabular}

المصدر: من إعداد الباحثين 
الخطوة الثانية: اختبار صدق وثبات الاستقصاء: وقد قام الباحثون باختبار قائمة الاستقصاء

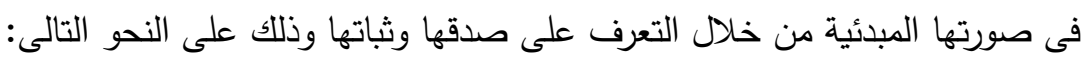
اختبار صدق الاستقصاء: اعتمد الباحثون على صدق مفردات الدراسة الميدانية، وذلك للتأكد من صلاحية قائمة الاستقصاء من الناحية العلمية وكذلك من الناحية التطبيقية، ويمكن توضيح ذلك بإيجاز فيما يلى:

صدق مفردات الدرلسة الميد/نسف: قام الباحثون بإختبار قائمة الاستقصاء فى صورتها المبدئية من خلال التعرف على صدقها وثباتها وذلك على النحو التالى:

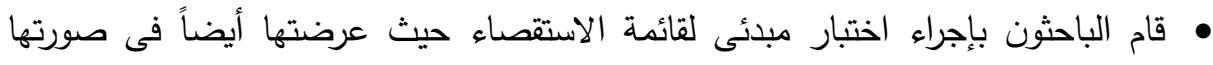
الأولية على ثلاثين فرداً من مجتمع الدراسة، وذللك للتأكد من بساطة الصياغة وباءة وضئه اللغة، وللتأكد أيضاً من صلاحية الاستقصاء من الناحية الميدانية. • تم إجراء اختبار ثبات للتأكد من إمكانية الاعتماد على نتائج الدراسة فى تعميم النتائج، التهاء

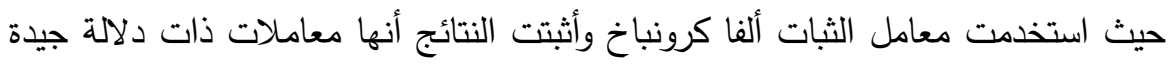
لتحقيق أهداف الدراسة بعد استبعاد بعض العبارات، ويمكن الاعتماد عليها فى تعميم النتائج على مجتمع الدراسة.

الخطوة الثالثة: استيفاء بيانات قوائم الاستقصاء واعدادها للتحليل الحصائي: قام الباحثون

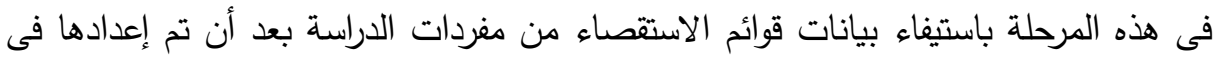
صورتها النهائية بعد استبعاد بعض العبارات التي لم يثبت صدقها وثباتها، حيث قام الباحثون بالتوجه إلى بعض المنشآت قيد الدراسة لعرض قوائم الاستقصاء على بعض العاملين عن طريق المقابلات الشخصية. هذا كما تم مراجعة قوائم الاستقصاء بعد أن تمت الإجابة عليها، ثم قام الباحثون بإدخال هذه البيانات للحاسب الآلى بعد تفريغها فى جداول خاصة، واستخدم الباحثون برنامج الحزم

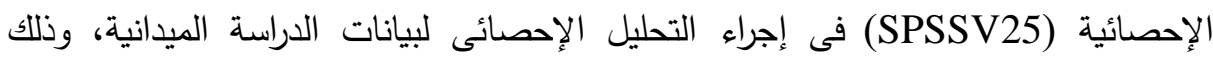
بالاستعانة بمكتب متخصص بالدراسات والتحليل الإحصائي. 
أساليب التحليل الإحصائي: اعتد الباحثون على الأساليب التالية: معامل الثبات (Alpha) كرونباخ: ويستخدم لحساب معامل الثبات، وذلك لبحث مدى إمكانية الاعتماد على نتائج الدراسة الميدانية في تعميم النتائج.

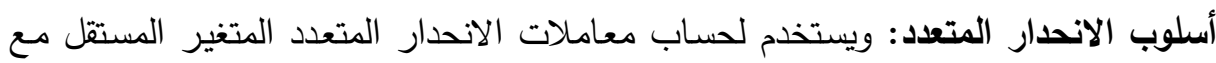

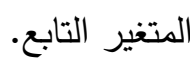
اختبار كروسكال • ولاس "Kruskal Walias Test: أحد الاختبارات اللامعلمية التي تستخدم لاختبار الفرق بين متوسطين. إن أنسب الاختبارات الإحصائية لهذا الشكل من البيانات هو اختبار كروسكال ـ ولاس لئس Kruskal Walias Test" القائل بعدم وجود فروق بين الصفوف الثلاثة (عينة الدراسة) فى استجاباتهم على أسئلة

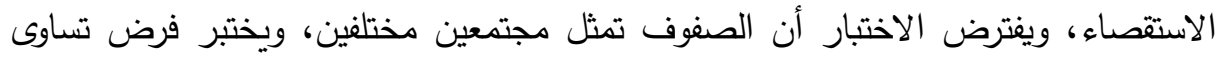

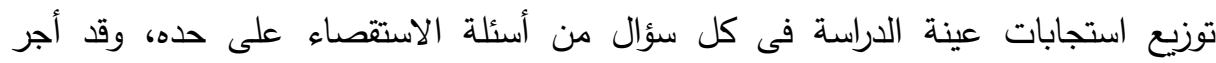

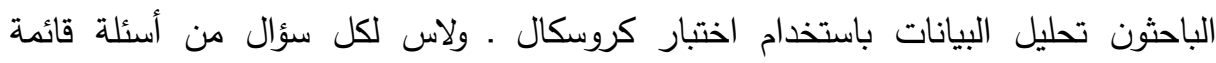


V25 فى إجراء التحليل الإحصائي لبيانات الدراسة الميدانية.

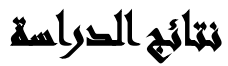

اختبارات الفروض وتحليل النتائج: ويتتاول الباحثون كل عنصر من العناصر السابقة بشيئ من التفصيل كما يلى: حساب معاملي الصدق والثبات: جدول معاملى الثبات لألفا كرونباخ والصدق الذاتى لاستمارة الاستقصاء. 
مجلة العلوم البيئية

معهد الدراسات والبحوث البيئية - جامعة عين شمس له له

جدول (ץ): مقاييس الاعتمادية Reliability لمحاور الدراسة

\begin{tabular}{|c|c|c|c|c|}
\hline الصدق(*) & ألفا (معامل & العبارات & توصيف المحور & الداسة \\
\hline •, 199 & $\cdot, \wedge \cdot \wedge$ & 10 & قياس قدرة المنظمة على تتمية الموارد & الأول \\
\hline$\cdot, 911$ & 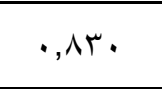 & r) & قياس قدرة المنظمة على تحقيق الميزة & 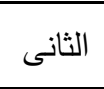 \\
\hline$\cdot, 904$ & $\cdot, 9 \cdot 1$ & r4 & قائمة الاستقصاء ككل & \\
\hline
\end{tabular}

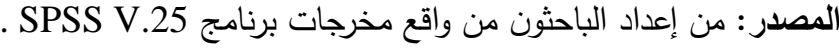

تم حساب معامل الصدق عن طريق جذر معامل الثبات: يتضح من الجدول السابق أن قيمة ألفا Cronbach 's Alfa قد بلغت ^,, •^\%، r^\%\%، كما انعكس ذلك على معاملات

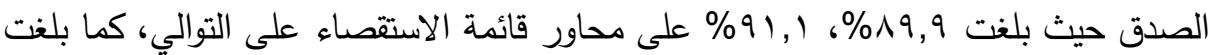

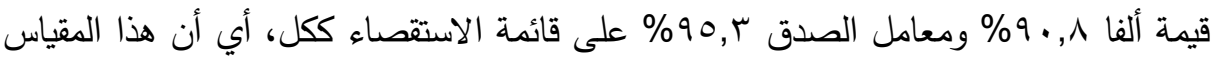



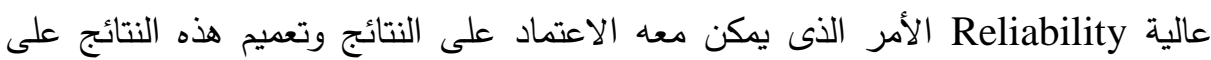
مجتمع الدراسة. ومن خلال قيمة معاملات الثبات والصدق يمكن القول أنها معاملات ذات دلالة جيدة

لتحقيق الهدف من الدراسة ويمكن الاعتماد عليها فى تعميم المخرجات على المجتمع ككل. اختبار الفروض وتحليل النتائج: اختبار الفرض الأول: توجد علاقة ارتباط جوهرية بين كفاءة وفعالية تتمية الموارد البشرية فى المنظمة وبين قدراتها التتافسية. وقد تم اختبار هذا الفرض من خلال دراسة علاقات الارتباط

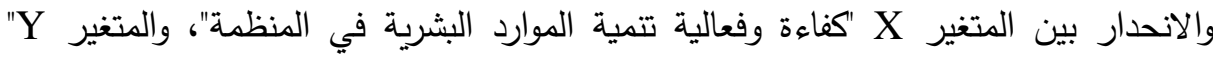
تدعيم القدرة التنافسية"، وجاءت النتائج كما يلي: علاقات الارتباط والاتحدار بين كفاءة وفعالية تنمية الموارد البشرية فى المنظمة وبين قدراتها التنافسية: بتطبيق أسلوب الارتباط والاتحدار بين كفاءة وفعالية تتمية الموارد البشرية فى المنظمة وبين قدراتها التنافسية جاءت النتائج كما يوضحها الجدول التالي:

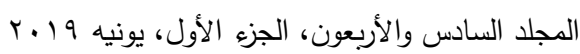


جدول (ץ): نتائج الارتباط والانحدار بين كفاءة وفعالية تنمية الموارد البشرية فى المنظمة وبين قدراتها التتافسية

\begin{tabular}{|c|c|c|c|c|c|c|c|}
\hline \multicolumn{8}{|c|}{ 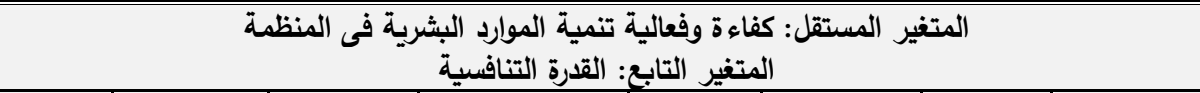 } \\
\hline المعتوية & المحسوبة T & قالمعامل & المعاملات & \multirow{2}{*}{ 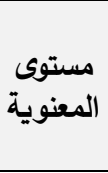 } & \multirow{2}{*}{ F } & \multirow{2}{*}{$\begin{array}{l}\text { التحديد } \\
\text { R2 }\end{array}$} & \multirow{2}{*}{$\begin{array}{c}\text { معامل الارتباط } \\
\text { R }\end{array}$} \\
\hline$\cdot, \cdots$ & $0, \mu_{r}$ & $1,0.71$ & $\begin{array}{c}\text { ثابت الانحدار } \\
\text { A }\end{array}$ & & & & \\
\hline$\cdot, \cdots$ & 10,10 & $\cdot, 7 \wedge \wedge$ & معامل الانحدار & $\cdot, \cdots$ & rrq, & • r & זוד, •("*) \\
\hline
\end{tabular}

(*) معنوي عند مستوى معنوية ا +,...

يتضح من الجدول ما يلي: أظهرت نتائج الارتباط الخطي وجود علاقة ارتباط طردية ذات

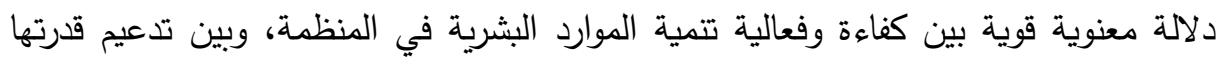

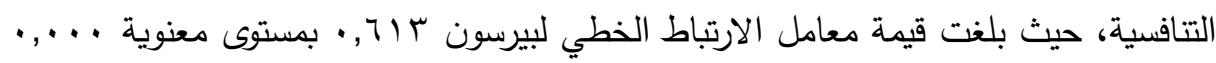
مما يعني معنوية العلاقة عند مستوى معنوية ا +,.•، أي أن زيادة كفاءة وفعالية تتمية الموارد البشرية في النظم يصاحبها زيادة في قدرتها التنافسية. بعد تقدير معالم نموذج الانحدار يمكن صياغة معادلة الانحدار بالثكل التالي: $\mathrm{Y}=1.061+0.688 * \mathrm{X}+\varepsilon$ $\begin{array}{rc} & Y \\ \text { كفاءة وفعالية تتمية الموارد البشرية في المنظمة التنافية } & X\end{array}$ حيث: ع $\quad$ ع

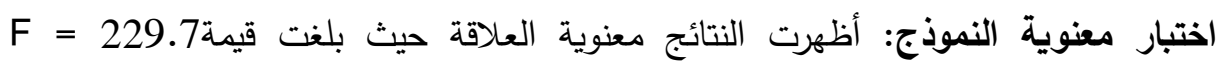

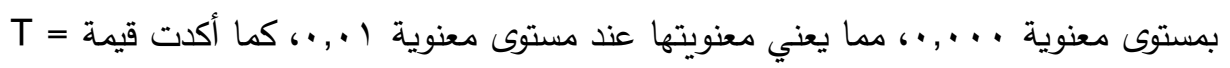

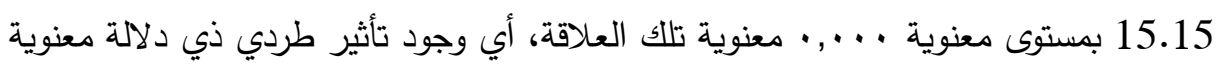

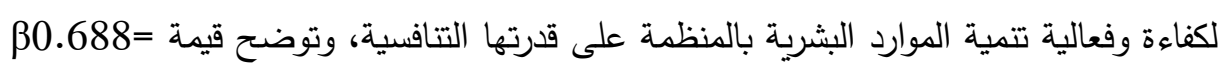
والتي تثير إلى قوة واتجاه التأثير، أي أن زيادة كفاءة وفعالية تتمية الموارد البشرية بدرجة

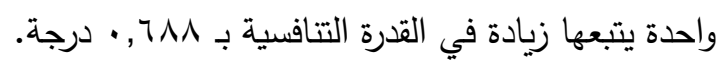


القدرة التفسيرية للنموذج: كما بلغت القدرة التفسيرية للنموذج ه orv\% وذللك من خلال قيمة

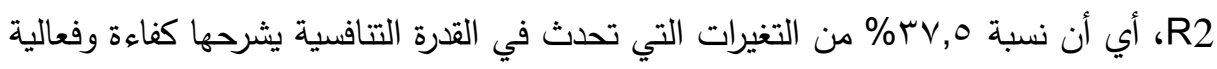
تنمية الموارد البشرية. نخلص من ذلك إلى قبول الفرض الأول للباحثين. اختبار الفرض الثاتى: توجد علاقة ارتباط جوهرية بين أسلوب تتمية الموارد البشرية بالمنظمة لإنئ ومستوى تدعيم القدرات التتافسية للمنظمة. ولاختبار ذللك الفرض تم إجراء الاهدئ الانحدار المتعدد

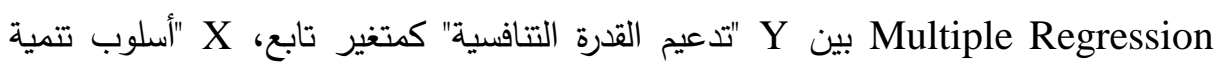
الموارد البشرية كمتغير مستقل، وحصلنا على النتائج التالية: جدول (؛): نتائج الانحدار المتعدد بين Y "تدعيم القدرة التتافسية" كمتغير تابع، X X "أسلوب تتمية الموارد البشرية" كمتغير مستقل

\begin{tabular}{|c|c|c|c|}
\hline \multicolumn{4}{|c|}{ المتغير التابع Y "القدرة التنافسية" } \\
\hline Sig. المعنوية & اختبار T & معاملات الانحدار & المتغير المستقل \\
\hline$\cdot, \cdots r$ & $r, \cdot T$ &., 710 & ثابت الانحدار (Constant) \\
\hline$\cdot, \ldots$ & 0,19 & $\cdot, \Gamma V \varepsilon$ & X أسلوب تتمية الموارد البشربة \\
\hline
\end{tabular}
Sig. =0.000 F = 148.8

من الجدول يتضح ما يلي: بعد تقدير معاملات الانحدار أخذ نموذج الانحدار الصيغة التالية $\mathrm{Y}=0.615+0.374 * \mathrm{X}+\varepsilon$ (القدرة التنافسية. X ع الخطأ العشوائي

يتضح من النموذج التأثير الطردي للمتغير المستقل على المتغير التابع كما يلي: وجود تأثر طردي ذو دلالة معنوية للمتغير X

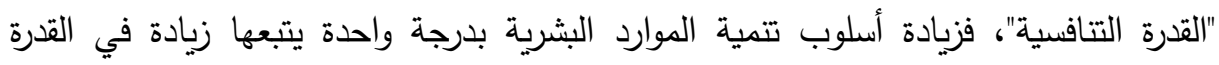

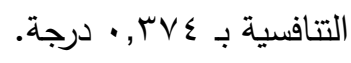


اختبار معنوية النموذج: بلغت قيمة F = 148.8 بمستوى معنوية أقل من ا .,. • مما يؤكد معنوية النموذج عند مستوى معنوية ال.,.•.

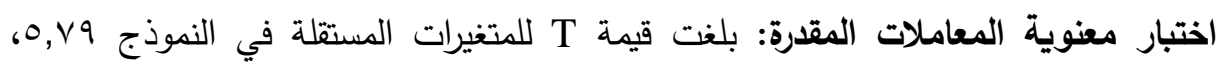

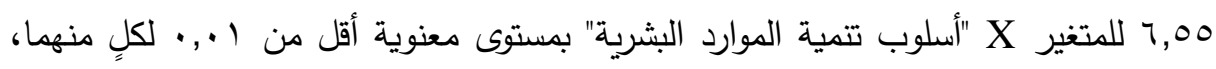

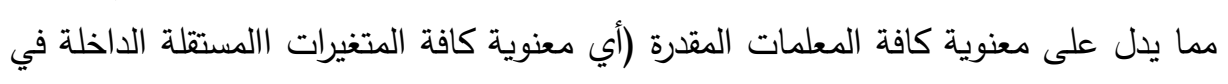
النموذج). القدرة التفسيرية للنموذج: بلغت قيمة R square = 0.439 ما مما يدل على أن المتغيرات

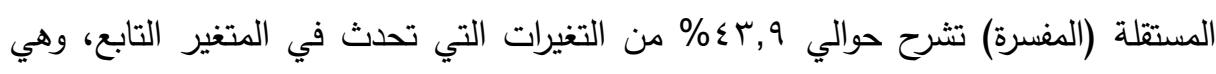
قدرة تفسيرية متوسطة. نخلص من ذلك إلى قبول الفرض الثانى للباحثون. ويتضح مما سبق وجود تأثير معنوي لأسلوب تتمية الموارد البشرية على تحقيق الميزة التنافسية.

\section{عنة المتائمة}

أهم نتائج الدراسة من وجهة نظر عينة الدراسة:

تم قبول الفرض الأول والذي تمت صياغته في صورة الإثبات "توجد علاقة ارتباط

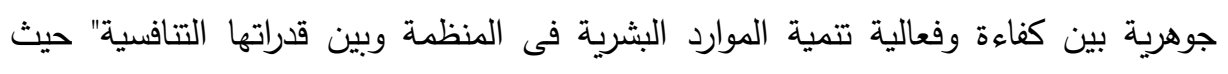

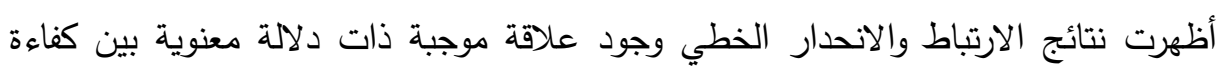

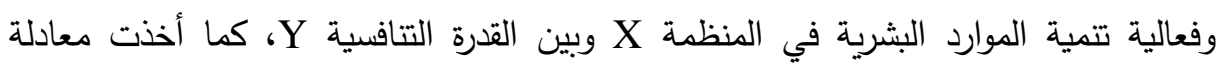
$\mathrm{Y}=1.06+0.688 * \mathrm{X}+\varepsilon$

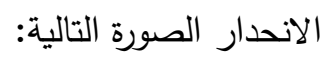

حيث: Y تدعيم القدرة التتافسية؛ X كفاءة وفعالية تتمية الموارد البشرية في المنظمة؛ ع الخطأ

$$
\text { العشوائي. }
$$

وقد ثبتت معنوية النموذج ومعنوية معامل الانحدار ، وبلغت القدرة التفسيرية له والمتمثلة

$$
\text { في قيمة معامل التحديد }
$$


تم قبول الفرض الثانى والذي تمت صياغته في صورة الإثبات "توجد علاقة ارتباط جوهرية بين

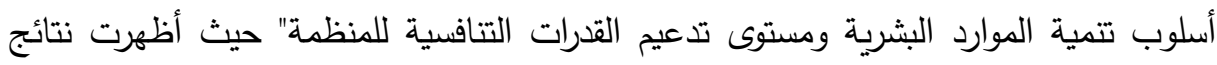
الارتباط والانحدار الخطي وجود علاقة موجبة ذات دلالة معنوية بين أسلوب تتمية الموارد البشرية X، وتدعيم القدرة التتافسية Y، كما أخذت معادلة الانحدار الصورة التالية: $\mathrm{Y}=0.615+0.374 * \mathrm{X}+\varepsilon$

حيث: Y القدرة التتافسية؛ X أسلوب تتمية الموارد البشرية؛ ع الخطأ العشوائي. وقد ثبتت معنوية النموذج ومعنوية معاملات الانحدار، وبلغت القدرة التفسيرية له له

$$
\text { والمتمثلة في قيمة معامل التحديد }
$$

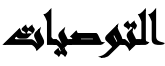

أظهرت النتائج الأثر الإيجابي لتتمية الموارد البشرية على تحقيق الميزة التنافسية

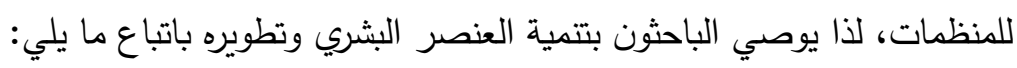

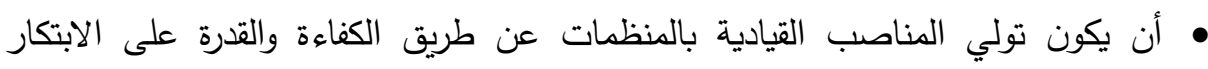

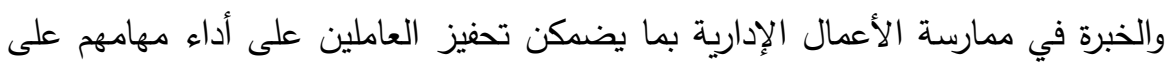
الوجه الأفضل. ألا يقتصر معيار التعيين على المؤهل العلمي، بل يجب أن يشتمل على الخبرات الفنية،

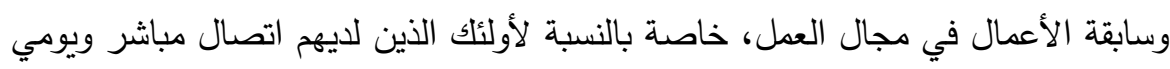
مع الزبائن، فهم مجبرون على ترك الطباع جيد هيد لصورة المنظمة. التركيز على أنشطة التطوير والبحوث والتدريب لتتمية القدرات الابتكارية والإبداعية للعاملين، ومتابعة العاملين الذين يتم تدريجهم لتقييمهم، ومتابعة الإنجازات التي يقدمونها.

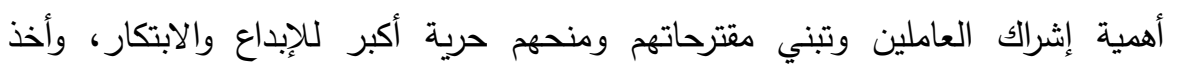

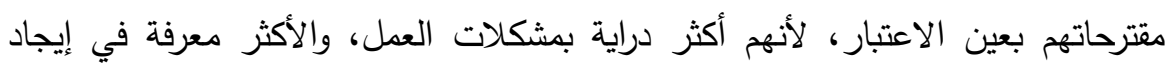
الحلول. 
• استخدام النظريات الحديثة وبصفة تدرجية في مجال تطوير وتتمية الموارد البشرية ضرورة مكافأة العاملين على الأفكار الابتكارية التي تدعم أنشطة المنظمة.

\section{المرالم:}

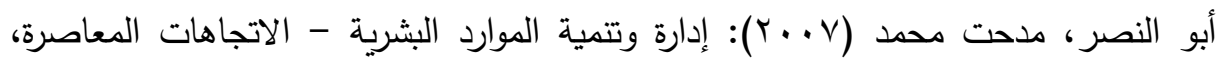

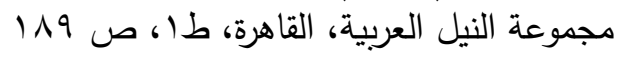

ابراهيم، خالد عبد الله: دور اتخاذ القرارات الادارية في تحقيق الميزة التتافسية - دراسة ميدانية

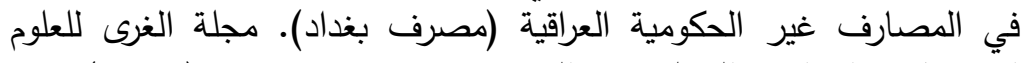

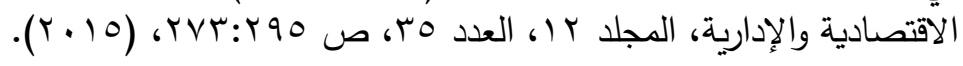

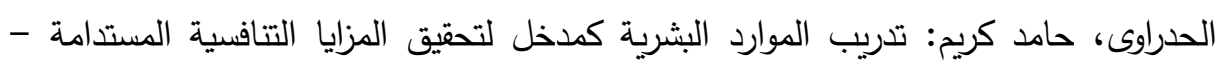

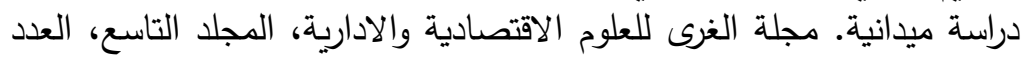

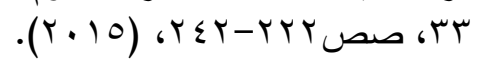

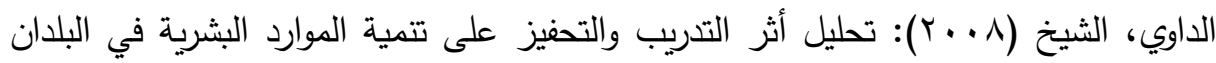

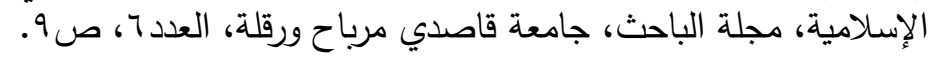

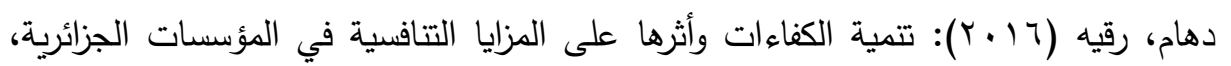

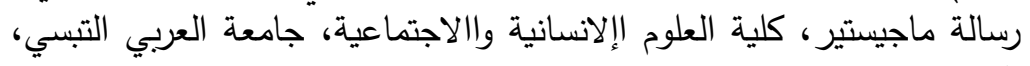

$$
\text { الجزائر • }
$$

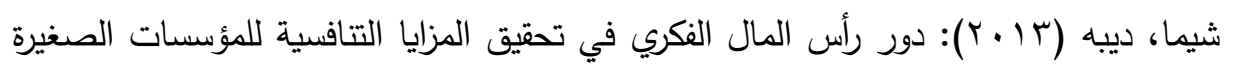

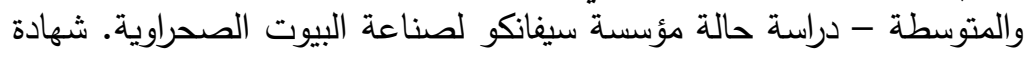

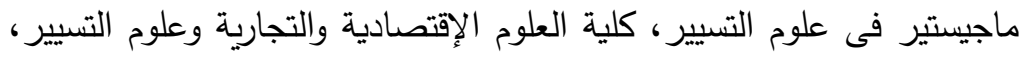
جامعة قاصدي مرباح.

عبدالحميد، عفاف السيد بدوي: رؤية استراتيجية لرأس المال الفكري ودوره في تحقيق المزايا

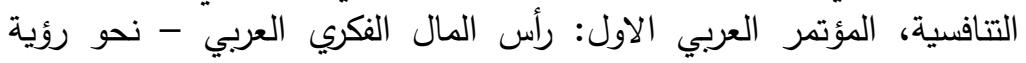

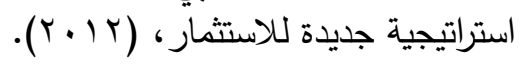

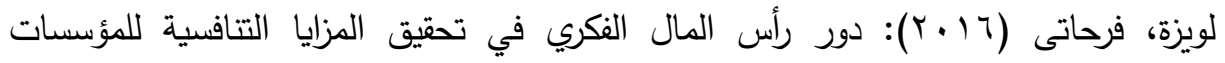

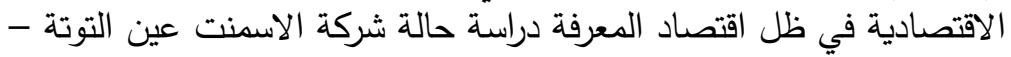

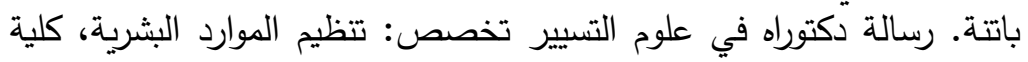

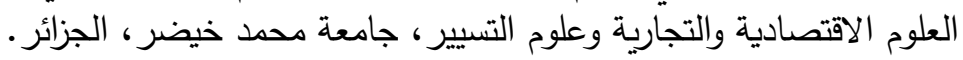




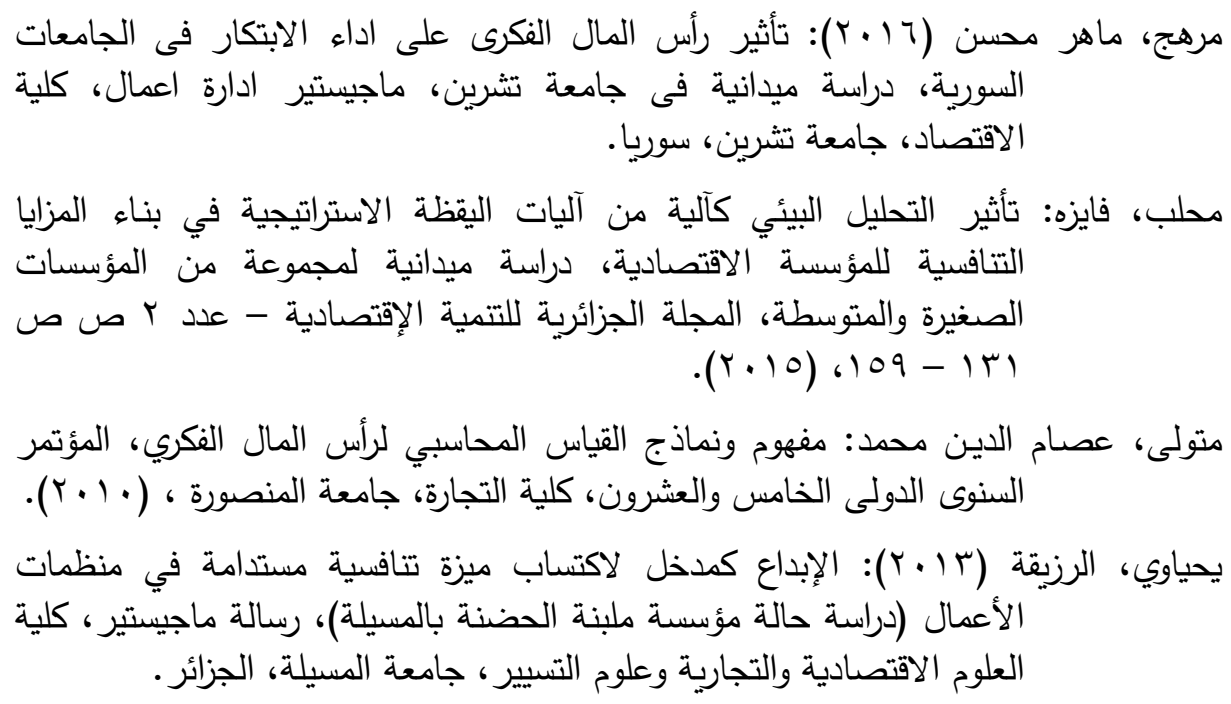

Aldulaimi, Saeed Hameed: Human Resources Performance Measurement Approaches Compared to Measures Used in Master's Theses in Applied Science University, International Review of Management and Marketing ISSN: 2146-4405 available at http: www.econjournals.com International Review of Management and Marketing, Vol 6, Issue 4, pp. (958-963) (2016).

Al-najjar, Fayez Jomah: Social Responsibility and its Impact on Competitive Advantage (An Applied Study on Jordanian Telecommunication Companies) International Journal of Business and Social Science, Vol. 7, No. 2, (2016).

Manroop, Laxmikant (2015): Human resource systems and competitive advantage: an ethical climate perspective, Business Ethics A European Review, Volume 24, Issue 2, Pages 111-220 
داليا صلاح الدين عطية العطار وآخرون

\title{
THE IMPACT OF HUMAN RESOURCES ON ACHIEVING COMPETITIVE ADVANTAGE FOR THE ORGANIZATION
}

\author{
Dalia S. A. El-Attar ${ }^{(1)}$; Gamal S. Khatab ${ }^{(1)}$ and Salah H. Salam ${ }^{(1)}$ \\ 1) Faculty of Commerce, Ain Shams University
}

\begin{abstract}
The goal of measuring the impact of human resources is to achieve competitive advantage to the Organization and applied it into industrial organizations, after identifying the level of perception and awareness of decision makers in the Egyptian industrial organizations about the importance of measuring the impact of human resources. To assess the importance of the human resources development to achieve competitive advantage for organizations.

The study discovered the links between the variables and access to the most important results of the study through theoretical analysis and statistical analysis of field study and showed the positive impact of the human resources development to achieve competitive advantage for organizations.
\end{abstract}

Keywords: Human Resources, Competitive Advantage. 